\title{
The Science fair in our school
}

\author{
M. Vavoulidou* \\ $I^{\text {st }}$ Primary School, Kilkis, Hellas.
}

Received 22 April 2008; Revised 1 December 2008; Accepted 20 December 2008

\begin{abstract}
Research in alternative learning incentives led us to a peculiar kind of learning resulting in remarkable outcomes. We are currently under a Science Fair Project -being outlined in this review - which was presented in our school on the 3rd \& 4th of March 2008.

The approach which was expanded (by the pupils of the 1st Primary School class SIXTH2) concerns an Environmental Education Project in correlation with the Natural Sciences.

This Science Fair is considered to be their final outcome of a long and praiseworthy assignment. It is an informal type of learning, which in combination with formal learning along with the learning process, makes up an incentive for children contributing to the creation of positive attitudes concerning the subject of Natural Sciences. Children are offered creative fulfillment through research processes, experiments and constructions. What is more, this Fair is not only an opportunity for parents to embark on the learning task but also the local community along with the local educational community as well. Children come in contact with various authorities and feel the satisfaction of presenting their work and their constructions to the Public, delivering messages for energy preservation - concerning the use of renewable and milder types of energy - thus contributing to the research of solutions considering scientific - ecological - sociable issues which threaten our planet
\end{abstract}

Keywords: Science fair, School, ecological, renewable.

\section{1. "Save the environment to save yourselves" An alternative teaching-learning approach}

A pupils first contact with the subject of Natural Sciences is fully noticed during the last couple of years in Primary School. Pupils have already formed premature conceptions (correctly or incorrectly) concerning Natural Phenomena. This fact, combined with students' learning capabilities, who are currently in the stage of specific logical reasoning, defines the teaching degree concerning the observatory level. Abstract concepts (as for example energy) are very hard to be taught to pupils belonging to the first schooling degree. However, according to Bruner's "spiral development of matter" any abstract concepts can be approached by pupils belonging to the first schooling degree, as long as these concepts are adapted to their age capabilities. The subject matter is taught starting from specific to general, from simple to complex and from easy to difficult points. Teaching becomes even more effective, provided that prior to the introduction of new concepts, students' empirical knowledge is taken advantage of, so that new knowledge is gradually emulated in the existing ones. The new analytical program and the new school manuals which adopt the researching model as a proposed teaching intervention, provide the cutting edge in active participation and the discovery of new knowledge by the pupils themselves, who follow specific cognitive-learning stages with the guiding coordination provided by their teacher [1]. The new analytical program is based on pre-existing knowledge so pupils follow a systematic researching route with chronologically ordered steps to reach new emulating elements. Thus, they familiarize themselves in a scientific working way even at this age, which gives them the satisfaction of success and whets the appetite of all pupils (regardless of their sex, their school performance, their social background, their learning difficulties and their descent).

However, to accept the subject, a pivotal role plays the research of alternative incentives for learning, which led us to a different type of learning having remarkable results. We coordinated a Science Fair - being presented in this reviewon the $3^{\text {rd }} \& 4^{\text {th }}$ of March 2008.

The "Science Fair" as it is referred to abroad and "Science Fair in our school" as we the students of class Sixth2 of the $1^{\text {st }}$ Primary School Kilkis call it, is an exhibition of assignments concerning various scientific issues from the field of Natural Sciences which are chosen, carried out and presented by pupils to visiting audiences. It is an alternative teaching method of Natural Sciences whose curriculum lies outbound legislated education. which whets children of this age appetite and has become favorable by them. The Science Fair is included in the curriculum of some countries' analytical educational program.

\footnotetext{
* E-mail address: Hvmaria@sch.gr

ISSN: 1791-2377 @ 2008 Kavala Institute of Technology. All rights reserved.
} 


\section{Subject choice}

The subject was chosen by the children themselves in this attempt as they were worried by the recent calamitous climatic changes and their dramatic consequences which showed their ugly face this previous summer.

Heat waves, sudden tempests, forest fires and flooding are observed more and more frequently. The climate is changing, environmental equilibrium since time immemorial is thwarting as all this leads to appallingly reversed circumstances. There are numerous signs of accelerated climatic change or global warming unfolding before us, and we are just in the beginning. Energy sources (crude oil, mined coal, natural gas) used to be considered infinite, now are reserved for only a couple of decades more. The Ozone Hole is still agape, acid rain destroys nature and the environment as a whole. Are we going to just be witnesses? Or must we, as future citizens of this country, haste and put pressure to governmental authorities to find solutions in common for a better and more viable future?

These were the children's inquisitions since the beginning of the school year. These puzzlements were taken advantage in the best possible way by materializing our project. The project commenced in October 2007 and ended in February 2008, lasting for 5 months. 25 pupils participated divided in 5 groups comprising 5 pupils each. The subject was divided in 5 sub-modular units by students themselves, this was decided partly to comprehend the multi-tasking of the subject and the thorough processing and studying of each special sector interacting with others. Each group undertook a sub-modular [2].

The sub-headings were the following :

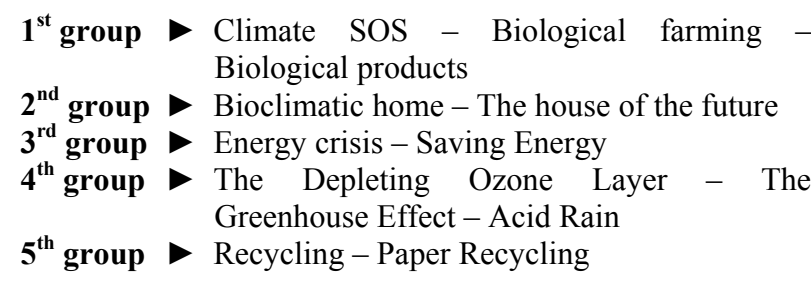

\section{Teaching Aims}

\section{Cognitive group:}

- to become informed about environmental threats and to correlate them with natural sciences.

- to obtain scientific knowledge on upcoming environmental threats

- to investigate specific experimental queries

- to comprehend energy type issues concerning human activities

- to form a positive attitude when it comes to renewable resources and their use in modern life

- to become acquainted with new technologies in researching and utilizing information

- to suggest viable solutions to avoid nasty consequences concerning human life in the near future

- to make their own constructions which will operate with solar power (solar ovens, bioclimatic homes, solar immersion heater)
- to invite various authorities and private entrepreneurs to our school premises to inform them on details concerning quarries they posed

\section{Emotional group :}

- to sensitize them on issues (resource depletion, quality of life in a clean and viable environment e.t.c. ) which they will face as future citizens

- to form or to change attitudes, values and behaviours to save the environment

- to acquire environmental consciousness

- to develop skills in solving issues concerning the global community

\section{Dealing with social issues group :}

- to concern themselves on issues which plague the global community

- to announce and deliver their message to their peers or to their wider social environment

- to learn how to discuss and how to cooperate to achieve their goals

- $\quad$ to present through a theatrical play their sensitivity and their concern for the endangered surroundings to pupils, to educators and to parents who visit the exhibition

- $\quad$ to comprehend that solidarity and group work lead to positive results concerning learning processes and character formation

- to contribute in their own way and their own capabilities to search for solutions concerning grave scientific-ecological-sociable issues threatening our planet

- to include pupils from other schools in their own dilemmas by playing and interacting with games already being prepared

\section{Methodology - Action}

Pupils worked in groups of 5, each group having 5 members. The forming of the groups took place after a sociometric test. The groups were mixed and dissimilar concerning their sex, descent nad their school performance. The pupils had distributed their roles within their group and defined their periodic role change within members at regular intervals. Group work was defined within the margins of their own sub-module was investigated by following these stages:

\section{A. Finding and exploiting data from various sources.}

Children searched for data concerning their sub-module from books, magazines, newspapers, public libraries, web pages and CD-ROMs. Information technologies and Communications contributed greatly to completing their painstaking work. Data collection was available to be utilized throughout this project.

\section{B. Field research}

Field research was utilized by 3 groups. Children undertook the role of their investigator in the school green house, where they planted their biological seeds. They were observing the development of their plants providing the necessary manual work and taking down the stages of their research. Another group took down notes from public 
institutions (e.g. the bioclimatic building KPE of Kordelio Thessaloniki). The third group was conducting experiments in the school yard. Pupils' experimental results outside the school classroom limits were magnificent in contrast to those conducted within the classroom walls.

Field Research as a pedagogic process is bearing fruit because:

1. it challenges pupils' interest in learning

2. pupils have direct management and experience of the subject matter

3. it facilitates learning, since the place is familiar and the pupils have already acquired the cognitive submodule [3]

C. Drafting questionnaires and interviewing representatives from local authorities and from the school community.

Pupils from two groups gladly undertook the role of the journalist interviewing people from their social and their school background.

D. Experimental investigations inside classrooms and outdoors in the yard.

The course below was folloed concerning experimental investigations:

- $\quad$ question formulations

- hypotheses formulations

- designing-structuring of the experiment

- conducting the experiment

- noting down observations and measurements

- concluding

- hypotheses verifications or annulments

- generalizations

A Chinese proverb professes "I hear and I forget, I see and I remember, I do and I understand". Lecturing methods and experiment showing from the teacher's bench, which are implemented to a great extent in the Hellenic schools, are considered to be outmoded teaching processes. Pupils rapidly forget what they have heard whereas they remember whatever they have carried out in experiments alone or within their group, as they are obligated to search for the materials needed, to hypothesize, to conduct the experiment, to observe and to conclude. Thus, they learn to work as scientists, learn to take the initiative, to rely on their own two feet and to learn to be objective [4].

All types of the investigation in the work sheets were prepared to facilitate children's work, to register conclusions and to notify their fellow students.

To deal with the construction of the solar immersion heater, the solar ovens and the bioclimatic home students had to negotiate issues such as:

- "energy and heat from the sun"

- "the green house effect"

- "energy transformations"

- " energy depletion"

- "acid rain"

So, experiments concerning "heating water with the help of sunrays" were conducted. They studied water heating in similar plastic containers, which were left for quite a long time under the sun containing the same amount of water. The one container was painted black and the other was left transparent. With the help of two thermometers they measured the temperatures concurrently inside both containers. They came to the conclusion that in the black container the temperature was far greater than in the other [5].

Another experiment was about "greenhouse models" made of the cardboard boxes previously holding the plastic containers from which the lids had been removed and were replaced by nylon. Some of them had not the lids removed. These were left exposed for a specific time under the sun rays and had their temperature measured from the inside. So, solar energy entrapment by nylon cardboards was comprehended.

The same experiment was conducted by placing inside the cardboard bottom various colorful cardboards and aluminum foil on the sides.

Another group of experiments was assigned concerning acid rain. Inside same-sized plastic containers bearing the same amount of water plants were planted. Drops from half a lemon were added in a container so that water would become acid. This was left unattented for a specific amount of time and then some observations were drown up.

Another experiment concerning acid rain was under way inside and outside the class bounds having office stationery provided by the environmental Education Board.

E. Activities with the aid of technology in the Information Technology laboratory

The internet was used as a tool to search for data and CDROMs for energy, energy sources, acid rain and the ozone hole were used.

Technologies which are already a reality in most of the Hellenic schools offer scaffolds on building up knowledge, provide the possibility to students to deal with more advanced level activities, to work out more demanding thinking abilities and to enhance their cognitive levels even if these students have learning difficulties [6].

Technologies contribute significantly to accepting the cognitive objectives of Physics Education by all students.

\section{F. Saving up energy constructions}

Crafting is a kind of manual work. Manual work which is not supported by contemporary schools provides the advantages of immediate and tangible outcomes. Dealing with their hands pupils have the opportunity to express themselves, to communicate, to voice their opinion, to cooperate, to program, to observe the stage of their work and to immediately realize their mistakes which are literally tangible, without theoretical formulations which many a time can be devoid of content. JJ Rousseau said that: "Hands working for the benefit of the spirit. Anyone becomes a philosopher at a time believing that he is a worker". [7]

The essence and the educational value of this whole venture combining formal and informal procedures is instrumental, as it seems that it arouses many of the conceptual, communicational and inventive characteristics which comprise a wider framework of "scientific knowledge upon action" having activities based on authentic issues and everyday situations. [5]

Children chose to construct solar ovens, a bioclimatic home which was later named "smart home" and "future 
home" as well as the solar immersion heater. These were among their interests, believing that they were going to provide answers to questions. They also considered that finding the materials to implement their experiments was fairly manageable.

These experiences were greatly enviable since they contained values of creativity and personal expression, their judgmental thought and problem solving abilities were enhanced leading to condusive active learning.

In this venture invaluable assistance was provided by the visit of a manufacturer who deals with immersion heaters. He paid a visit to our classroom as the pupils could not witness the process of manufacturing, as planned, since there was a necessary removal in his factory premises elsewhere.

As for the bioclimatic home, a visit to Thessaloniki's KPE (Center Environmental Education), which is itself a biobuilding, in Kordelio was successfully accomplished. Pupils had the chance to draw information by up close observation and by realizing which are the energy saving secrets of this bio-building. Pupils had also invited a mechanics engineer in the classroom premises to acquire information on energy saving houses.

Below are some process steps concerning the construction of the solar ovens which was presented in the Science Fair. Simple, mainly useless materials were used so as not to be thrown away but to be utilized for the second time. Used pizza cartons, aluminum foil, glue, gelatin, blackcolored cardboard and insulating material (sponge) were brought by the pupils. Sun light goes through gelatin and is absorbed by the black-colored cardboard which was placed on the bottom of the pizza box, so the bright sun rays are transformed into heating energy. Solar radiation is reflected by the aluminum foils placed along the upright lid of the box. Thus, solar radiation is captivated inside the box and the temperature is risen so much so that food can be cooked. Eggs synny side up were successfully cooked.

As for the construction of the solar immersing heater which presented some obstacles, useless material was searched for. Students decided to construct an open type of heater as it was considered to be far less demanding. Large cardboard boxes with lids on were gathered, half an inch black rubber, glass, glue, solid polystyrene, plastic water containers and plastic corners. Part of a large cardboard lid was cut off and a margin of 3 centimeters was left to install a piece of glass. The cardboard was insulated with black solid polystyrene and black rubber was placed inside so that both ends could have access to a water collector deposit. The water collector deposit was connected with the rubber having both ends at different heights (one higher than the other). Cold water beingheavier lies in the bottom of the container whereas warmer water being lighter rises upwards. To construct a bioclimatic home, rigid cardboard, bluecolored solid polystyrene, plexiglass, a piece of wood, screwing twists, colors, and pieces of cloth were brought by the pupils. Its size was designed, its orientation was agreed upon, the materials needed for an energy saving home were gathered, what is needed for its shade in the summer was concluded as well as its greenhouse location. Pupils worked in the evenings to finalize their constructions.

\section{G. Other experimental activities}

Paper recycling was widely agreed upon. Paper recycling bins were placed in each and every classroom and the paper was collected on a predestined day each week. Then it was put inside the larger recycling bin which can be found outside the school yard premises. This paper is collected at regular intervals by Kilkis municipality specialized trucks. This group of children recycled paper inside their classroom and a recyclable book was made containing various messages as well as the names of the firms which recycle paper.

Bookmarks were made containing messages for a viable environment, saving energy, renewable energy resources use, biological cultivations, wise water usage suggesting solutions for our planet viability.

Posters were made to inform their school as well as all the rest local school communities about the Science Fair. Invitations were printed to invite and sensitize the other school communities concerning the Science Fair.

Crosswords and acronyms were made to embark student visitors.

\section{H. Theatrical play scenario}

The pupils composed a theatrical play scenario pertaining to saving up energy, resources and their wise utilization. This theatrical play carried a dual meaning. On the one hand elements of spontaneity, expression, creativity and team work are included, on the other hand, it is considered an activity of "experimental action and labor" [8] though which learning surfaces effortlessly, normally and pleasurably. It is indicative to instill meanings for which students are inexperienced, such as the meaning of energy. [9]

This dramatization as well as the interactive games which children prepared (crosswords and acronyms ) contributed significantly to the project's evaluation as a worthwhile effort by the pupils themselves, the students and the teachers from other school units who have visited and participated in it.

\section{I.Interventions}

At the beginning of the project a meeting with the children's parents was arranged to make them aware and to ask for their cooperation concerning their involvement in the project. Afterwards a letter was sent concerning the interventions going to take place during the project. Their cooperation was of great value to children's proceedings as well as to reach conclusions.

Children belonging to the recycling group overviewed their house waste for a week and classified it in 4 categories: organic, paper, glass, plastic. Every day the waste belonging to each category was weighted and written down. A quantitative superiority of organic waste matter was noticed. Children belonging to the group of saving energy made sure to follow some of their own suggestions-solutions to contribute to the energy issue : they turned off the lights from places they were to longer present, they switched off all electrical appliances from the stand by mode, the washing machine was preset to function at lower temperature rates, they reduced by 1 degree the temperature inside their homes.

\section{Evaluation of the science fair - outcomes}

According to the approach developed concerning the Environmental Education Project in correlation with Natural Sciences from the students of class Sixth2, the Science Fair which lasted for two consecutive days, comprised the final outcome of their long and praiseworthy efforts. It was 
considered to be an informal way of learning which in relation to both formal learning and learning process, provided the incentive for pupils. It also largely contributed to creating positive attitudes concerning the subject of Physics. Pupils were sensitized in environmental issues which currently concern and will continue to concern the global community, they were also motivated to seek for resolutions to those issues. Learning of new concepts and acquisition of new knowledge was achieved through numerous alternative routes which were mentioned and transported to the post- knowledge level which was our main aim. Theoretic knowledge was combined with innovative manual constructions.
Creativity satisfaction was offered to pupils through experiments and constructions. Moreover, this Science Fair was considered an opportunity to demand not only parents' participation but also the local community as well as the local educational community. Children came into contact with the local authorities and experienced the satisfaction not only from their outcomes and constructions' presentations but from the interaction with other school pupils through the games they had prepared.

At the end of the Science Fair a letter to the $1^{\text {st }}$ Primary School Principal was given containing suggestions to ecologically transform the school since the south facing orientation prerequisites were discovered to be met.

\section{References}

1. Depps n.s. class sixth, fek 1336 vol. B

2. Matsagouras Il. G., "Cross-curricular in school knowledge Meaning centered reframing and assignment Framing and projects", Edit. Grigori, Athens 2003

3. Kamarinou D., "Experimental Learning at school", B Edit. 1999

4. Kokkotas P Environmental Education, Korinthos, 23-25 September 2005. V., "Teaching Natural Sciences", Edit. Grigori, Athens 1999

5. Tsagliotis N., "Solar Energy? Yes, Thank you!", $1^{\text {st }}$ Congress School Programs
6. Kokkotas P. V., "Teaching Natural Sciences Part II- Contemporary Approaches to Natural Sciences Teaching- Constructive Approach to Teaching and to Learning",Edit.P. B. Kokkota, Athens 2004

7. Chrysafidis K., "Experimental-Communicative Teaching", GUTENBERG, Athens 2000

8. Grammatas Th., "Theater for children and youth audiences", Edit. Dardanos Typothito Athens 1996

9. Driver R.,Squires A., Rushworth P., Wood-Robinson V., "Ecoconstructing the meanings of Natural Sciences", Edit. Dardanos Typothito, Athens 2000 